\title{
Effect of Doppler Bandwidth on the Performance of Channel Sounding
}

\author{
Jun-Ho Jo ${ }^{1}$ and Seyeong Choi ${ }^{2^{*}}$ \\ ${ }^{1}$ Network Strategy BU, KT \\ ${ }^{2}$ Dept. of Information \& Communication Eng., Wonkwang University \\ 도플러 대역폭이 채널 추정의 성능에 미치는 영향 \\ 조준호 ${ }^{1}$, 최세영 $2^{*}$ \\ ${ }^{1}$ 한국 통신 \\ ${ }^{2}$ 원광대학교 정보통신공학과
}

\begin{abstract}
In this work, we consider the effect of doppler bandwidth on the performance of channel sounding. We develop the mathematical formulation of the problem and compare the MMSE channel estimator to the simple correlator. Examples of the performance of the MMSE and correlator estimators are presented for the single-input single-output (SISO) case with various values of Doppler bandwidth to assess the impact of time variation. The results show that as the $f_{d} T$ product increases the performance of both the MMSE and correlator estimates gets worse, and that the performance of the MMSE estimator improves relative to the correlator.We also consider case that the exact statistics of the channel are unknown It is shown that when the mismatch is not too large, the MMSE estimator with mismatch still does better than the simple correlator, but if the mismatch is large, then the correlator can do better.

요 약 본 연구에서는 도플러 대역폭이 채널 사운딩에 미치는 영향을 고려한다. 이를 위해 먼저 수학적인 공식을 전개한 후에 단순한 상관기와 MMSE를 비교한다. 시간 변화의 영향을 평가하기 위하여 MMSE와 상관기의 성능은 SISO 환경 하에서 다양한 도플러 대역폭 값을 적용하여 분석한다. 시뮬레이션 결과를 통하여 $f_{d} T$ 값이 증가할수록 MMSE와 상관기의 성능은 더 열화되며 MMSE의 성능은 상관기에 비해 향상됨을 보인다 또한 정확한 채널 정보가 알려져 있지 않을 경우의 성능 열화에 대해서도 고려한다. 채널 정보의 부정확도가 낮을 경우에는 여전히MMSE의 성능이 좋지만 채널 정보의 부정 확성이 커질수록 상관기의 성능이 더 좋아짐을 보인다. 본 연구는 기존에 직관적으로 시행해 왔던 MMSE와 성관기의 성 능 분석을 위한 시뮬레이션에 추가적으로 수학적인 접근법을 제공하여 그 응용분야를 넓혀 갈 수 있음을 보인다.
\end{abstract}

Key Words : Channel Sounding, Doppler Bandwidth, MMSE, SISO

\section{Introduction}

In this work, we consider the Minimum Mean Square Estimation (MMSE)[1,2] of channel parameters based on a discrete time model of the time varying channel. We develop the mathematical formulation of the problem and compare the MMSE channel estimator to the simple correlator. Examples of the performance of the MMSE and correlator estimators are presented for the single-input and single-output (SISO) case with various values of Doppler bandwidth[3,4] to assess the impact of time variation. The results show that as the $f_{d} T$ product increases the performance of both the MMSE and correlator estimates gets worse, and that the performance

This work was supported by Wonkwang University in 2012.

${ }^{*}$ Corresponding Author : Seyeong Choi (Wonkwang University)

Tel: +82-63-850-6882 email: sychoi@wku.ac.kr

Received August 7, 2013

Revised (1st October 4, 2013, 2nd October 14, 2013)

Accepted November 7, 2013 
of the MMSE estimator improves relative to the correlator.

We also present some results regarding the degradation in performance of the multiple-input and multiple-output (MIMO) estimator when the exact statistics of the channel are unknown. It is shown that when the mismatch is not too large, the MMSE estimator with mismatch still does better than the simple correlator, but if the mismatch is large, then the correlator can do better.

\section{The Effect of Doppler Bandwidth on Channel Estimation}

In the application of MIMO[3-5] channel sounding[6-9], there are at least two related effects of the Doppler bandwidth[10]. One is that if the separate transmit antennas are excited at different times the channel will change somewhat between the two measurements and the estimates will not represent the channel at the same instant of time. Another related effect is that even when one transmit antenna only is excited the channel may change during the measurement interval, resulting in measurement distortion. Let us address the second effect first. The MMSE estimation attempts to mitigate the measurement distortion effect by exploiting knowledge of the channel time correlation. We will compare the performance, in Doppler, of the MMSE estimator and the simple correlator. In the next section we derive the error in the correlator case, to prepare the comparison.

\subsection{The Correlator Method}

If we assume $\mathrm{h}$ is constant and

$$
\mathbf{X}(n)=\left[\begin{array}{c}
x(n) \\
x(n-1) \\
x(n-2) \\
\cdot
\end{array}\right],
$$

then, the output can be written as

$$
\mathbf{y}=\left[\begin{array}{c}
y(1) \\
y(2) \\
y(3) \\
\cdot \\
\cdot \\
y(N)
\end{array}\right]=\left[\begin{array}{c}
\mathbf{X}^{*}(1) \\
\mathbf{X}^{*}(2) \\
\mathbf{X}^{*}(3) \\
\cdot \\
\cdot \\
\mathbf{X}^{*}(\mathrm{~N})
\end{array}\right] \mathbf{h}=\left[\begin{array}{c}
w(1) \\
w(2) \\
w(3) \\
\cdot \\
w(N)
\end{array}\right]
$$

or

$$
\mathrm{y}=\mathrm{X}^{*} \mathrm{~h}+\mathrm{w}
$$

where $\mathrm{X}=[\mathrm{X}(1) \mathrm{X}(2) \cdots \mathrm{X}(\mathrm{N})]^{T}$.

If we choose $\mathrm{h}$ to minimize $\left\|\mathrm{y}-\mathrm{X}^{*} \mathrm{y}\right\|^{2}$, then we have

$\hat{\mathrm{h}}=\left(\mathrm{XX}^{*}\right)^{-1} \mathrm{Xy}$.

From (2), we can have

$\mathrm{Xy}=\left(\mathrm{XX}^{*}\right) \mathrm{h}+\mathrm{Xw}$.

Using (3) and (4), we estimate $\mathrm{h}$ based on $\mathrm{y}$ as

$$
\begin{aligned}
& \hat{\mathrm{h}}=\left(\mathrm{XX}^{*}\right)^{-1} \mathrm{Xy} \\
& =\mathrm{h}+\left(\mathrm{XX}^{*}\right)^{-1} \mathrm{Xw}
\end{aligned}
$$

Finally, we have

$$
\hat{\mathrm{h}}-\mathrm{h}=\left(\mathrm{XX}^{*}\right)^{-1} \mathrm{Xw}
$$

For illustration purposes we consider a $2 \times 2$ case in the diagram as shown in Fig. 1.

\subsection{MSE calculation for the Correlator}

To calculate MMSE, we consider error covariance matrix. Let error $=\{\mathrm{h}-\hat{\mathrm{h}}\}=\mathrm{e}$, then error covariance matrix is

$$
\begin{aligned}
& E\{(\mathrm{~h}-\hat{\mathrm{h}})(\mathrm{h}-\hat{\mathrm{h}}) *\}=E\left\{\mathrm{e} \mathrm{e}^{*}\right\} \\
& =\left[\begin{array}{cccc}
E\left\{\mathrm{e}_{1} \mathrm{e}^{*}{ }_{1}\right\} & E\left\{\mathrm{e}_{1} \mathrm{e}^{*}{ }_{2}\right\} & \cdots & \cdots \\
E\left\{\mathrm{e}_{2} \mathrm{e}^{*}{ }_{1}\right\} & E\left\{\mathrm{e}_{2} \mathrm{e}_{2}\right\} & \cdots & \cdots \\
\vdots & \vdots & \ddots & \vdots \\
\vdots & \vdots & \cdots E\left\{\mathrm{e}_{N} \mathrm{e}_{N}^{*}\right\}
\end{array}\right]
\end{aligned}
$$

where

$$
\mathrm{e}=\left[\begin{array}{c}
e_{1} \\
e_{2} \\
\vdots \\
e_{N}
\end{array}\right] .
$$

Now, the resulting mean squared error covariance matrix will be

$$
K=E\{(\mathrm{~h}-\hat{\mathrm{h}})(\mathrm{h}-\hat{\mathrm{h}}) *\}=E\{(\mathrm{~h}-\hat{\mathrm{h}})(\mathrm{h}-\mathrm{My}) *\}
$$

since $E\left\{\right.$ error $\left.\cdot \mathrm{y}^{*}\right\}=0$.

We have

$$
\begin{aligned}
& K=E\{(\mathrm{~h}-\hat{\mathrm{h}})(\mathrm{h}-\hat{\mathrm{h}}) *\}=\mathrm{E}\left\{(\mathrm{h}-\hat{\mathrm{h}}) \mathrm{h}^{*}\right\} \\
& =E\left(\mathrm{hh}^{*}\right)-\mathrm{M} E\left(\mathrm{yh}^{*}\right) \\
& =E\left(\mathrm{hh}^{*}\right)-\mathrm{M} E\left(\mathrm{hy}^{*}\right)^{*} \\
& =\mathrm{R}_{h h}-\mathrm{R}_{h y} \mathrm{R}_{y y}^{-1} \mathrm{R}_{h y}{ }^{*}
\end{aligned}
$$

The trace of $K$ represents the total error variance of the MMSE

From (6), we can let $\mathrm{M}=\left(\mathrm{XX}^{*}\right)^{-1} \mathrm{X}$. Then 


$$
\begin{aligned}
K_{\text {correlator }}= & E\left\{\left(\mathrm{~h}\left(n_{0}\right)-\hat{\mathrm{h}}\left(n_{0}\right)\right)\left(\mathrm{h}\left(n_{0}\right)-\hat{\mathrm{h}}\left(n_{0}\right)\right) *\right\} \\
= & E\left\{\left(\mathrm{~h}-\mathrm{M}_{\text {correlator }} \mathrm{y}\right)\left(\mathrm{h}-\mathrm{M}_{\text {correlator }} \mathrm{y}\right)^{*}\right\} \\
= & \mathrm{R}_{h h}-\mathrm{R}_{h y} \mathrm{M}^{*}{ }_{\text {correlator }}-\mathrm{M}_{\text {correlator }} \mathrm{R}^{*}{ }_{h y} \\
& +\mathrm{M}_{\text {correlator }} \mathrm{R}_{y y} \mathrm{M}^{*}{ }_{\text {correlator }}
\end{aligned}
$$

The trace of $K_{\text {correlator }}$ represents the total error variance of the correlator. The next few figures show a comparison of measurement error using the MMSE method vs. a simple correlator method.

\section{Simulation Results}

Here we use an M-sequence of length 511 as the sounding signal. The channel has an exponential power delay profile with $L=511$ and decay parameter $\alpha=10$. The average signal to noise power ratio is $\mathrm{SNR}=30 \mathrm{~dB}$. The figures show the ratio of the power (in $\mathrm{dB}$ ) for each estimated channel tap to the error variance for the corresponding tap, for both the simple correlator and the MMSE estimator. The tap number corresponds to the delay in samples. The Doppler bandwidth (indicated by the $f_{d} T$ product) is varied in the figures to show its effect on both estimators. Unless otherwise stated, the value of $n_{0}$ in all the figures is $n_{0}=N / 2$,i.e., we estimate the channel impulse response at the mid-point of the received time interval.

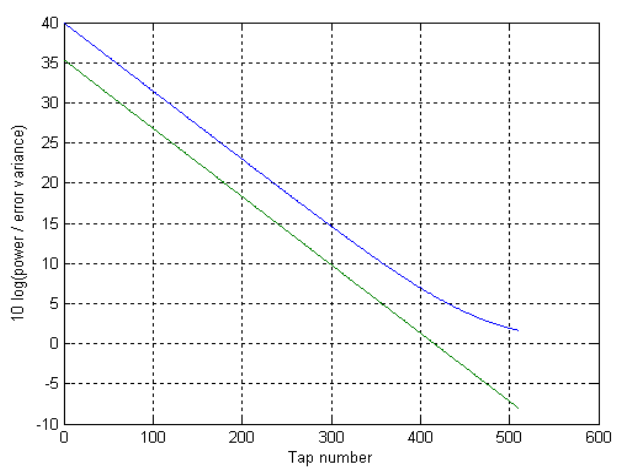

[Fig. 1] MMSE vs. Correlator with $f_{d} T=0$

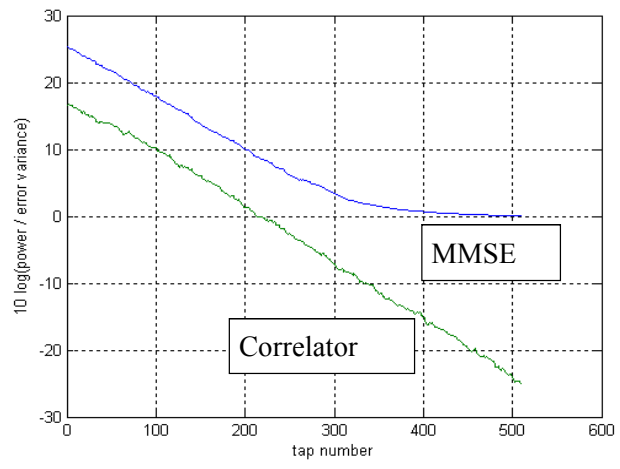

[Fig. 2] MMSE vs. Correlator with $f_{d} T=0.3$

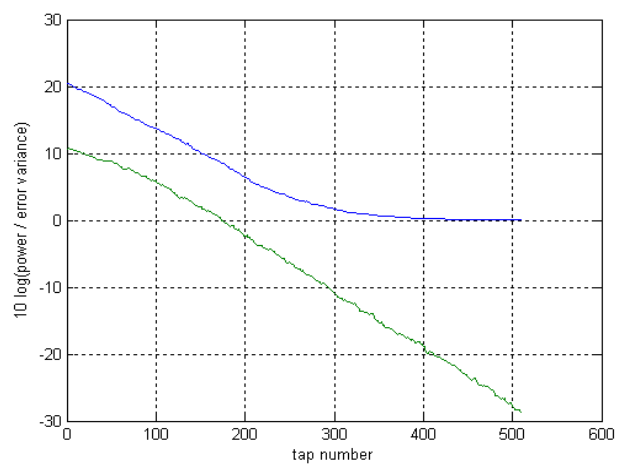

[Fig. 3] MMSE vs. Correlator with $f_{d} T=0.5$

In the next few figures the only change is that now $\mathrm{SNR}=50 \mathrm{~dB}$.

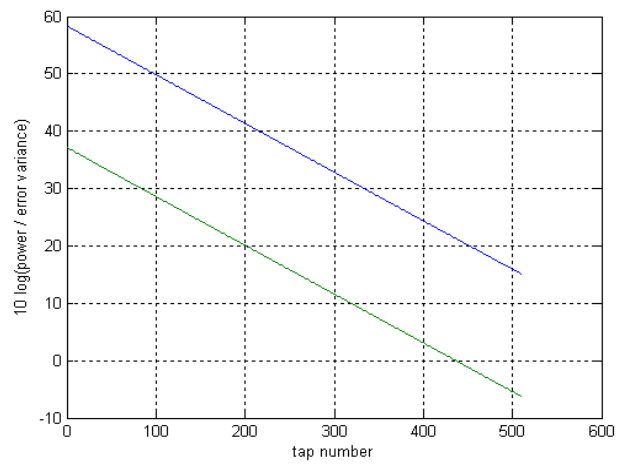

[Fig. 4] MMSE vs. Correlator with $f_{d} T=0$ 


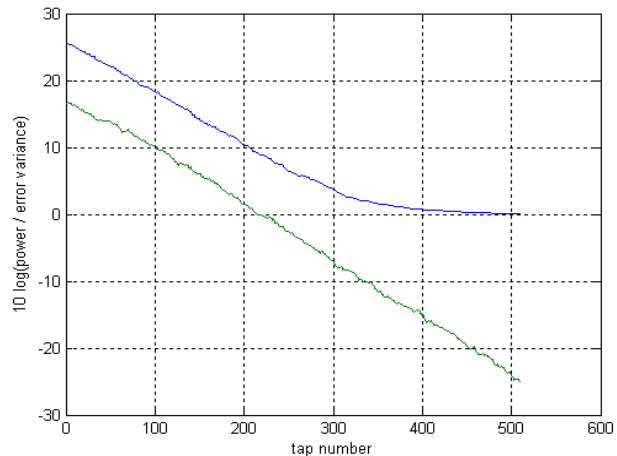

[Fig. 5] MMSE vs. Correlator with $f_{d} T=0.3$

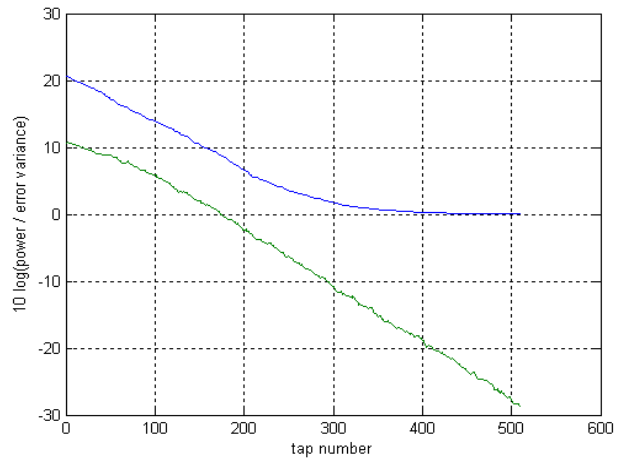

[Fig. 6] MMSE vs. Correlator with $f_{d} T=0.5$

In the next two figures we use an M-sequence of length 2047 as the sounding signal. The channel has an exponential power delay profile with $L=2047$ and decay parameter $\alpha=10$. The average signal to noise power ratio is $\mathrm{SNR}=30 \mathrm{~dB}$.

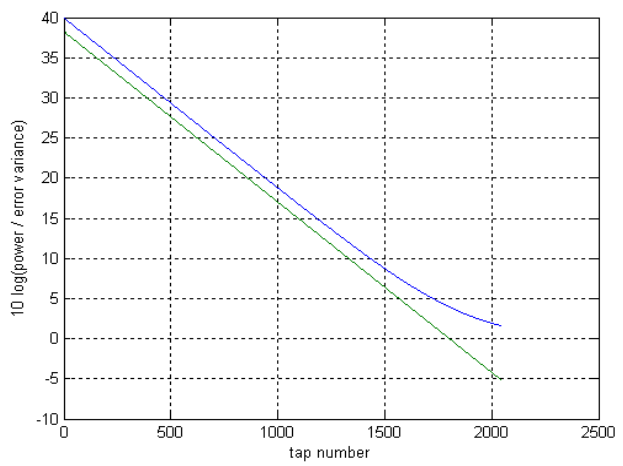

[Fig. 7] MMSE vs. Correlator with $f_{d} T=0$

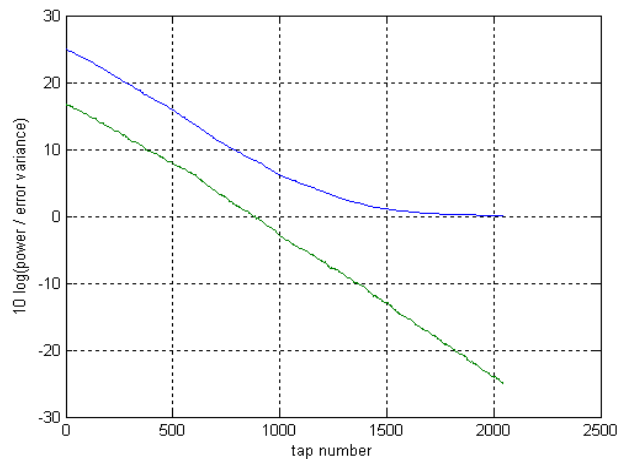

[Fig. 8] MMSE vs. Correlator with $f_{d} T=0.3$

If we know channel statistics, MMSE is better than correlator because correlator depends on noisy measured values but MMSE chooses zero mean rather than poor estimator.

\section{Statistics Mismatch}

So far we have assumed that the channel sounding receiver has exact knowledge of the statistics of the channel. Next we demonstrate the effect of a mismatch at the receiver. The first set of figures shows the effect of a mismatch in the assumed Doppler bandwidth. On each curve is a graph of the MMSE estimator with mismatch, as well as the correlator estimator for comparison. We let true signal is $r_{\text {true }}$ with $\mathbf{R}_{h h_{-} \text {true }}$ and received signal is $r_{\text {rec }}$ with $\mathrm{R}_{h h_{-} \text {rec }}$. Receiver estimate channel can be written as

$$
\hat{\mathrm{h}}\left(n_{0}\right)=\mathrm{My}=\left(\mathrm{R}_{h y}\right)_{r e c}\left(\mathrm{R}_{y y}\right)_{r e c}^{-1} \mathrm{y} .
$$

Error covariance matrix is

$$
\begin{aligned}
K_{\text {mis_match }}= & E\left\{\left(\mathrm{~h}\left(n_{0}\right)-\hat{\mathrm{h}}\left(n_{0}\right)\right)\left(\mathrm{h}\left(n_{0}\right)-\hat{\mathrm{h}}\left(n_{0}\right)\right) *\right\} \\
= & E\left\{\left(\mathrm{~h}-\mathrm{M}_{\text {mis_match }} \mathrm{y}\right)\left(\mathrm{h}-\mathrm{M}_{\text {mis_match }} \mathrm{y}\right)^{*}\right\} \\
= & \mathrm{R}_{\text {hh_true }}-\mathrm{R}_{\text {hy_true }} \mathrm{M}^{*}{ }_{\text {mis_match }} \\
& -\mathrm{M}_{\text {mis_match }} \mathrm{R}^{*}{ }_{\text {hy_true }} \\
& +\mathrm{M}_{\text {mis_match }} \mathrm{R}_{\text {yy_true }} \mathrm{M}^{*}{ }_{\text {mis_match }}
\end{aligned}
$$

The trace of $K_{\text {mis_match }}$ represents the total error variance.

Here we use an M-sequence of length 511 as the sounding signal. The channel has an exponential power 
delay profile with $L=511$ and decay parameter $\alpha=10$. The average signal to noise power ratio is $\mathrm{SNR}=30 \mathrm{~dB}$.

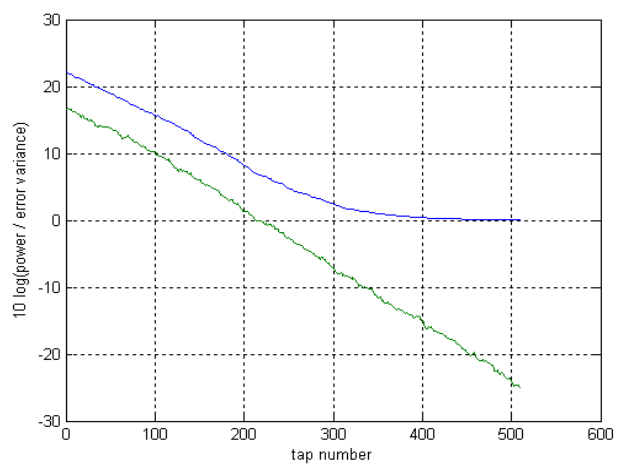

[Fig. 9] Mismatch case with $\left(f_{d} T\right)_{\text {true }}=0.3$, $\left(f_{d} T\right)_{\text {assumed }}=0.5$.

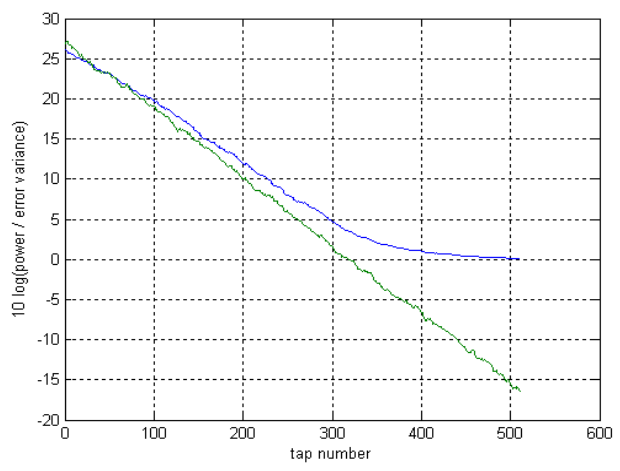

[Fig. 10] Mismatch case with $\left(f_{d} T\right)_{\text {true }}=0.1$, $\left(f_{d} T\right)_{\text {assumed }}=0.3$.

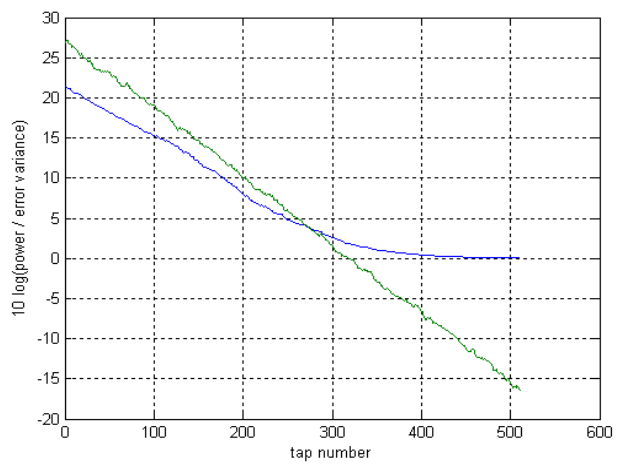

[Fig. 11] Mismatch case with $\left(f_{d} T\right)_{\text {true }}=0.1$, $\left(f_{d} T\right)_{\text {assumed }}=0.5$.
We can see from these figures that if the statistical mismatch is poor, then the correlator can outperform the MMSE estimator.

\section{Conclusions}

We considered the effect of doppler bandwidth on the performance of channel sounding by developing the mathematical formulation of the problem and comparing the MMSE channel estimator to the simple correlator. From the results it has been shown that as the $f d T$ product increases the performance of both the MMSE and correlator estimates gets worse, and that the performance of the MMSE estimator improves relative to the correlator. We also presented some results regarding the degradation in performance of the MMSE estimator when the exact statistics of the channel are unknown. It is shown that when the mismatch is not too large, the MMSE estimator with mismatch still does better than the simple correlator, but if the mismatch is large, then the correlator can do better.

\section{References}

[1] Yang-Seok Choi, Peter J. Voltz, and Frank A. Cassara, "On Channel Estimation and Detection for Multicarrier Signals in Fast and Selective Rayleigh," IEEE Trans. Commun., vol. 49, no. 8, pp. 1375-1387, Aug. 2001. DOI: http://dx.doi.org/10.1109/26.939860

[2] Yi Jiang, Varanasi, M.K, and Jian Li, "Performance Analysis of ZF and MMSE Equalizers for MIMO Systems: An In-Depth Study of the High SNR Regime," IEEE Trans. Inf. Theory, vol. 57, no. 4, pp. 2008 2026, 2011.

DOI: http://dx.doi.org/10.1109/TIT.2011.2112070

[3] A. Goldsmith, S. A. Jafar, N. Jindal, and S. Vishwanath, "Capacity limimts of mimo channels," IEEE J. Sel. Areas Commun., vol. 21, no. 5, pp. 684 - 702, Jun. 2003.

DOI: http://dx.doi.org/10.1109/JSAC.2003.810294

[4] G. L. Stuber, Principles of Mobile Communication, 2nd ed. Norwell, MA: Kluwer Academic Publishers, 2001

[5] M. K. Simon and M.-S. Alouini, Digital Communication over Fading Channels, 2nd ed. New York, NY: John 
Wiley \& Sons, 2005.

[6] N. N. Tran, H. D. Tuan, and H. H. Nguyen, "Superimposed Training Designs for Spatially Correlated MIMO-OFDM Systems," IEEE Trans. Wireless Commun., vol. 9, no. 3, pp. 876-880, Mar. 2010.

DOI: http://dx.doi.org/10.1109/TWC.2010.03.080661

[7] H. D. Tuan, H. H. Kha, and H. H. Nguyen, "Optimized Training Sequences for Spatially Correlated MIMO-OFDM," IEEE Trans. Wireless Commun., vol. 9, no. 9, pp. 2768-2778, Sept. 2010.

DOI: http://dx.doi.org/10.1109/TWC.2010.070710.081601

[8] Hlaing Minn and Naofal Al-Dhahir, "Optimal Training Signals for MIMO OFDM Channel Estimation," IEEE Trans. Wireless Commun., vol. 5, no. 5, pp.1158-1168, May 2006.

DOI: http://dx.doi.org/10.1109/TWC.2006.1633369

[9] X. Ma, L. Yang and G. B. Giannakis, "Optimal Training for MIMO Frequency-Selective Fading Channels," IEEE Trans. Wireless Commun., vol. 4, no. 2, pp.453-466, Mar. 2005.

DOI: http://dx.doi.org/10.1109/TWC.2004.842998

[10] W. C. Jakes, Microwave Mobile Communications, 2nd ed. Piscataway, NJ: IEEE Press, 1994.

\section{Seyeong Choi [Regular member]}

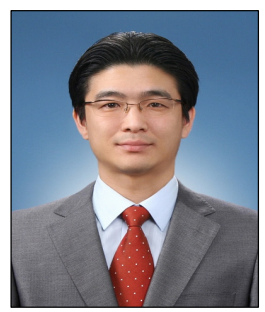

- Feb. 1998 : Hanyang Univ., MS

- Aug. 2007 : Texas A\&M Univ., $\mathrm{PhD}$

- Sept. $2008 \sim$ Feb. 2010 : LG Electronics, Engineer

- Mar. 2010 current : Wonkwang Univ., Dept. of Infor. \& Commun. Eng, Assistant Professor

$<$ Research Interests $>$ Wireless Mobile Communications 